\title{
To Evaluate the Efficacy of Vitamin-D as an Add- on Therapy in Patients with Allergic Rhinitis
}

\section{Resu Neha Reddy ${ }^{1}$, Vadlakonda Sruthi ${ }^{2}$, Sharath Chandra Goud C. ${ }^{3}$, Sowmini K. ${ }^{4}$}

Section: Healthcare

Sci. Journal Impact

Factor: 6.1 (2018)

ICV: 90.90 (2018)

cc) (i) (8)

Copyright@IJCRR

\author{
Junior Resident, Department of Pharmacology, Osmania Medical College, Hyderabad, Telangana - 50oo95, lndia; '²unior Resident, \\ Department of Pharmacology, Osmania Medical College, Hyderabad, Telangana - 500o95, lndia; ${ }^{3}$ MS Otorhinolaryngology, AllMS, Ri- \\ shikesh, Uttarakhand - 249203, India; 4]unior Resident, Department of Pharmacology, Osmania Medical College, Hyderabad, Telangana \\ -500095 , India
}

\section{ABSTRACT}

Introduction: Allergic rhinitis (AR) is a Type $1 \mathrm{lgE}$ mediated hypersensitivity disorder, characterized by sneezing, rhinorrhea, nasal congestion, itching, and postnasal drip. Recently, many studies reported that vitamin $D$ plays a critical role in Allergic rhinitis however, this association yet remains unclear.

Aim \& Methodology: The study aims to evaluate total nasal symptom scores (TNSS), serum IgE, serum absolute eosinophil count $(A E C)$ in patients of AR, pre and post-treatment with and without supplementation of vitamin D. The randomized, open-labelled, parallel-group study, including 100 patients randomized in 1:1 allocation. Group A received fluticasone nasal spray alone, group B received vitamin D (1000 IU once daily) plus fluticasone nasal spray for 3 weeks. The results of TNSS, serum IgE, serum AEC in patients with AR, pre and post-treatment with and without supplementation of vitamin $D$ were compared and evaluated.

Results: The mean difference pre and post-treatment in TNSS (group $A=6.553$, group $B=7.551)$, serum $\lg E(A=81.05$, $B=$ 109.92), serum AEC $(A=79.29, B=97)$ showed no statistical significant difference between two groups $(P$-value $\geq 0.05)$.

Conclusion: In this study, supplementation of vitamin D did not alter the natural course of Allergic rhinitis. Though changes in the symptoms and lab values were noted in between the groups, it was statistically not significant which would prove beneficial for the patients.

Key Words: Allergic rhinitis, Serum Absolute Eosinophil Count levels, Serum IgE levels, Serum vitamin D levels, Total nasal symptom score, Vitamin D supplementation.

\section{INTRODUCTION}

Allergic rhinitis (AR) also known as Pollenosis or Hay fever, is Type 1 IgE mediated hypersensitivity disorder. Allergic rhinitis is characterized by sneezing, rhinorrhea, nasal congestion, itching, and postnasal drip. ${ }^{1}$ Allergic rhinitis results in sleep disturbances, weakness, depressed mind-set, deplete subjective capacity of cognition, understanding that impedes the quality of life, efficiency, and productivity. ${ }^{2}$ Allergic rhinitis is the most common allergic disease worldwide, affecting around 10 to $25 \%$ of the population. ${ }^{3}$ Around 20 to $30 \%$ of Indian population experience and suffer no less than one allergic disorder. ${ }^{4}$ Reported prevalence of AR in India ranges between $20 \%$ and $30 \% .^{1}$ It affects a large percentage of pediatric patients and causes a notable number of school days missed every year. The impedance of work in adults also exists, influencing the finances of patients indirectly through lost workdays and directly through medicinal services cost spent on the disease. ${ }^{5}$ Triggering factors of AR are domestic allergens such as mites, insects, domestic animals or of plant origin; occupation-related triggers such as latex; common outdoor allergens such as pollens; automobile fumes; tobacco smoke; aspirin and other non-steroidal anti-inflammatory drugs (NSAIDs). The severity of the AR symptoms can be measured subjectively by total nasal symptom score (TNSS) and objectively by investigating the serum IgE and absolute eosinophil count (AEC) levels. The current guidelines suggest Intranasal corticosteroids (INSs) as first-line treatment for patients with moderate to serious AR, especially when nasal congestion is the prominent manifestation. ${ }^{6}$ INSs inhibit the inflammatory response and reduce the number of inflammatory cells,

\section{Corresponding Author:}

Vadlakonda Sruthi, Vadlakonda Sruthi, Junior Resident, Department of Pharmacology, Osmania Medical College, Hyderabad, Telangana 500095, India; Phone: 9490944596; Email: sruthivadlakonda90@gmail.com

ISSN: 2231-2196 (Print)

Received: 09.07.2020
ISSN: 0975-5241 (Online)

Revised: 14.08 .2020

Accepted: 05.09 .2020
Published: 22.09 .2020 
nasal mucosa permeability and the release of mediators. The current characterization of Allergic rhinitis as proposed by ARIA (Allergic Rhinitis and its Impact on Asthma) guidelines based on 1) Severity and quality of life as "mild" or "moderate-severe", 2) Duration as "intermittent" or "persistent" disease. ${ }^{7}$ Patients with Intermittent AR have sneezing, watery secretions, and eye symptoms; while patients with persistent AR have mucous secretions, nasal obstruction, postnasal drip, smell disturbances and may be associated with chronic sinusitis and asthma. In persistent AR patients, the above inflammatory responses occur in the respiratory tract.

A 2019 PAN-India study observed 70 to $90 \%$ of Indians are deficient of vitamin D. ${ }^{8,9,10}$ In recent studies, vitamin D is associated with an immune-modulator effect on naïve and activated helper T-cells, which could be beneficial in Allergic rhinitis. Most of these studies utilized serum $25(\mathrm{OH}) \mathrm{D}$ level of $30-80 \mathrm{ng} / \mathrm{ml}$ as normal level, $20-30 \mathrm{ng} / \mathrm{ml}$ as vitamin D insufficiency, and $<20 \mathrm{ng} / \mathrm{ml}$ as vitamin D deficiency. Vitamin D mechanism of action regulated the performance of macrophages, toll-like receptors (TLR), and natural killer cells (NK), as well as most of the Th2 cell-mediated components. The reaction of type 1 hypersensitivity of Allergic rhinitis was characterized by releasing various mast cell mediators. ${ }^{11}$ Inhibition process of Allergic rhinitis pathophysiology by vitamin D may reduce the clinical nasal symptoms. ${ }^{9}, 12,13$ Recently, many studies reported that vitamin D plays a critical role in Allergic rhinitis, however, this association yet remains unclear. The study aimed to evaluate total nasal symptom scores (TNSS), serum IgE, serum absolute eosinophil count (AEC) in patients of AR, pre and post-treatment with and without supplementation of vitamin D.

\section{METHODOLOGY}

A Randomized, open-labelled, prospective, parallel-group study, conducted in Allergic clinic of Government E.N.T. Hospital, Koti, Hyderabad for a duration of 6 months from May 2019 to Oct 2019. Patients showing signs and symptoms of Allergic rhinitis were selected for this study. Institutional Ethics Committee Approval was taken. The study was registered under Reg.No. ECR/300/Inst/AP/2013/RR-16. Written informed consent was obtained from all study participants of age more than 18 years in a prescribed format in regional language after explaining about study procedures. For the patients less than the age of 18 years, their parents were explained about the procedures, and written informed consent was obtained from them. If the participant was illiterate, the left thumb impression was taken.

Screening: After getting informed consent, 109 patients were screened. Out of 109 patients with Allergic rhinitis, 100 patients who satisfy the inclusion and exclusion criteria were enrolled in the study during 1st visit are randomized in 1:1 allocation.

\section{Inclusion criteria:}

Age: 18 - 60 years.

Both male and female patients.

Serum Vitamin D level $<30 \mathrm{ng} / \mathrm{ml}$.

Clinical symptoms for at least 1 month or more.

TNSS: $7-15$.

Patients willing to come for follow-ups as advised.

\section{Exclusion criteria:}

Age $<18$ and $>60$ years.

Co-morbid diseases that affect serum vitamin D levels.

Patients on oral or inhaled corticosteroids and medications including vitamin supplements.

Any nasal pathology.

Debilitating medical illness.

Pregnant or nursing women.

Non-consenting individuals.

Randomization: The enrolled patients were randomized by simple randomization (odd/even number) method into group A and group B.

Treatment Plan: Group A - Fluticasone nasal spray (2 puffs/ $50 \mathrm{mcg}$ in each nostril twice daily) for 3 weeks. Group B Vitamin D (1000 IU once daily) plus Fluticasone nasal spray ( 2 puffs $/ 50 \mathrm{mcg}$ in each nostril twice daily) for 3 weeks.

Assessment of Patients: Pre and post-treatment TNSS, serum vitamin $\mathrm{D}, \mathrm{Ig} \mathrm{E}, \mathrm{AEC}$ levels were done. The total nasal symptom score (TNSS) questionnaire was assessed based on signs like nasal congestion, runny nose, nasal itching, sneezing, and postnasal drip. ${ }^{14}$ The nasal symptoms like nasal congestion, runny nose, nasal itching, sneezing, and postnasal drip were assessed by interviewing the patients and graded according to severity.

Grade 0: None - No symptoms;

Grade 1: Mild - Symptom clearly present but easily tolerated;

Grade 2: Moderate- Symptom bothersome but tolerable;

Grade 3: Severe- Symptom difficult to tolerate, interferes with activity.

By adding each point of nasal symptoms, the total score of TNSS is obtained. The ARis graded depending upon the severity and total score as

1. Mild $\leq 6$;

2. Moderate 7 to 10 ;

3. Severe 11 to 15 . 
Statistical analysis: The observations and results were tabulated accordingly and data was analyzed using the Software Package for the Social Sciences (SPSS). Statistical significance between two drugs was evaluated using student's ttest. P-value of $\leq 0.05$ was considered significant.

\section{RESULTS}

Among 100 patients included in the study, 51 patients were male and 49 patients were female. During the study, 4 patients were excluded, out of which 3 patients were not willing to participate, consent was withdrawn and 1 patient end of the study visit not possible. Thus, Group A included 47 patients and group B included 49 patients after dropouts. The age distribution of all the patients included in the study is shown in figure 1 . Serum vitamin D was considered insufficient with the levels between $21-30 \mathrm{ng} / \mathrm{ml}$ and deficient if the levels were $\leq 20 \mathrm{ng} / \mathrm{ml}$. The serum vitamin D levels of the participants are shown in figure 2. The mean difference in total nasal symptom score (TNSS) between the two groups is shown in table 1 . The mean difference in serum $\operatorname{IgE}$ levels between the two groups is shown in table 2. The mean difference in serum absolute eosinophil count levels (AEC) between the two groups is shown in table 3. There was no statistically significant difference in TNSS, serum IgE and serum AEC levels between the two groups.

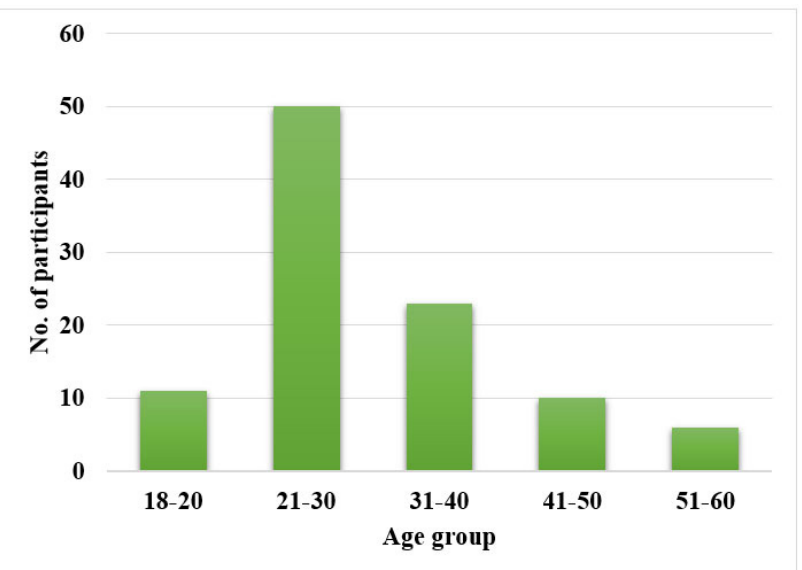

Figure 1: Age distribution.

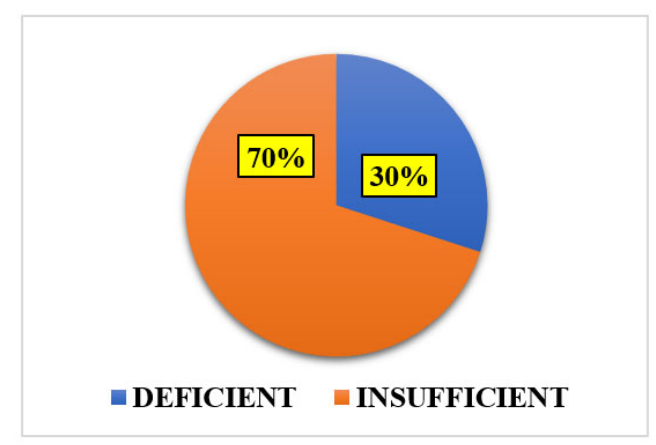

Figure 2: Serum Vitamin D levels in all the patients.
Table 1: Mean difference in total nasal symptom score (TNSS)

\begin{tabular}{llllc} 
& Group & N & Mean & P-value \\
Mean difference in & A & 47 & 6.553 & \\
TNSS & B & 49 & 7.551 & 0.091 \\
\hline
\end{tabular}

Table 2: Mean difference in serum IgE levels

\begin{tabular}{llccc} 
& Group & N & Mean & P-value \\
Mean difference in & A & 47 & 81.05 & \\
serum IgE & B & 49 & 109.92 & 0.705 \\
\hline
\end{tabular}

Table 3: Mean difference in serum absolute eosinophil count (AEC)

\begin{tabular}{lllll} 
& Group & N & Mean & P-value \\
Mean difference in AEC & A & 47 & 79.29 & \\
& B & 49 & 97.00 & 0.479 \\
\hline
\end{tabular}

\section{DISCUSSION}

Hyppönen et al. used a sample of subjects born in Finland in 1966 to examine the associations between infant vitamin D supplementation and adulthood allergic conditions. They found that the incidence of Allergic rhinitis (they identified Allergic rhinitis when participants experienced allergic cold - related to animal or pollen contact, e.g. hay fever - during the past 12 months) was higher in participants who had received vitamin $\mathrm{D}$ supplementation regularly during their first year of life compared to those who had not received supplementation at the age of 31 years. ${ }^{15}$ In another subsequent study, Wjst and Hyppönen analyzed the relationship between serum $25(\mathrm{OH}) \mathrm{D} 3$ values and AR prevalence in adults using the Third National Health and Nutrition Examination Survey (NHANES III) survey in Germany and found that the prevalence of Allergic rhinitis increased by $25(\mathrm{OH}) \mathrm{D} 3$ levels in all sub-groups and subsequent adjustments for gender, time and region of evaluation. ${ }^{16}$ Findings from these two studies indicated that in infancy or high levels of $25(\mathrm{OH})$ D3 supplementation of vitamin D was positively correlated to adult prevalence of Allergic rhinitis. Dogru and Suleyman compared serum 25(OH)D3 levels in children with Allergic rhinitis, according to the Allergic Rhinitis and its Impact on Asthma [ARIA] 2008 guidelines or non-allergic rhinitis (NAR) with the control group and found that mean serum $25(\mathrm{OH})$ D3 levels of both Allergic rhinitis and Non-allergic rhinitis children were lower than the control group.${ }^{17}$ But there was no association between the levels of $25(\mathrm{OH}) \mathrm{D} 3$ and the frequency, severity, and extent of allergic rhinitis. In another study in Iran, Arshi et al. assessed 25(OH)D values in Allergic rhinitis patients and compared the results with the general population (no control group) and found that the prevalence of severe 25 
$(\mathrm{OH}) \mathrm{D}$ deficiency in Allergic rhinitis patients was significantly higher than the normal population. ${ }^{18}$ From the above studies, we can see that only two studies described Allergic rhinitis according to ARIA, and both reported a negative association between levels of vitamin D and Allergic rhinitis. ${ }^{17,18}$ There are conflicting conclusions about the relationship between levels of vitamin D and the risk of Allergic rhinitis. For example, after supplementation, one study reported significantly reduced IgE values in atopic patients. ${ }^{19}$ However, Back et al. reported that children supplemented with vitamin $\mathrm{D}(>13 \mathrm{mg} /$ day) showed an increased risk of either AR or allergic asthma. ${ }^{20}$ In particular, the intake of vitamin D led to an increased risk of AR at the age of 6 when there was already a positive family history for AR. Similarly, Hypponen et al. showed that during infancy dietary intake of vitamin D promoted allergic diseases at the age of $31 .{ }^{16}$ In addition to supporting a deleterious role in supplementing vitamin D, Milner et al. found that early supplementation of the vitamin in children was associated with increased risk of asthma and food allergies..$^{21} \mathrm{Few}$ studies reported that vitamin D suppresses the development of T helper 1 cells (Th1 cells) but augments T helper 2 cells (Th2 cells) differentiation which increases IL-4, IL-5, IL10 and Ig E production. The results of our study are in contrast with other previous published literature. This may be due to change in the study population, seasonal variation, sample size and duration of the study.

\section{CONCLUSION}

In this study, supplementation of vitamin D did not alter the natural course of Allergic rhinitis. Though changes in the symptoms and lab values were noted in between the groups, it was statistically not significant which would prove beneficial for the patients. Further studies are required in large sample sizes and different study designs to evaluate the efficacy of vitamin D supplementation in patients with Allergic rhinitis.

\section{ACKNOWLEDGEMENT}

Authors thank Dr. T. Chakradhar, Professor and Head, Department of Pharmacology for expert advice. We also thank Dr. Souris Kondaveti for valuable opinions. Authors acknowledge the immense help received from the scholars whose articles are cited and included in references to this manuscript. The authors are also grateful to authors/editors/publishers of all those articles, journals and books from where the literature for this article has been reviewed and discussed.

\section{Conflict of Interest: Nil}

Source of Funding: Nil

\section{REFERENCES}

1. Varshney J, Varshney H. Allergic rhinitis: an overview. Indian Journal of Otolaryngology and Head \& Neck Surgery. 2015;67(2):143-9.

2. Camelo-Nunes IC, Sole D. Rinite alergica: indicadores de qualidade de vida. Jornal Brasileiro de Pneumologia. 2010;36(1):12433.

3. Deb A, Mukherjee S, Saha BK, Sarkar BS, Pal J, Pandey N, Nandi TK, Nandi S. Profile of patients with allergic rhinitis (AR): a clinic based cross-sectional study from Kolkata, India. Journal of clinical and diagnostic research: JCDR. 2014;8(1):67.

4. Prasad R, Kumar R. Allergy situation in India: what is being done?

5. Schoenwetter WF, Dupclay L, Appajosyula S, Botteman MF, Pashos CL. Economic impact and quality-of-life burden of allergic rhinitis. Current medical research and opinion. 2004;20(3):305-17.

6. Bousquet J, Van Cauwenberge P, Ait Khaled N, Bachert C, Baena Cagnani CE, Bouchard J, Bunnag C, Canonica GW, Carlsen $\mathrm{KH}$, Chen YZ, Cruz AA. Pharmacologic and anti-IgE treatment of allergic rhinitis ARIA update (in collaboration with GA2LEN). Allergy. 2006;61(9):1086-96.

7. Bousquet J, Van Cauwenberge P, Khaltaev N. Allergic rhinitis and its impact on asthma. Journal of allergy and clinical immunology. 2001 Nov 1;108(5):S147-334.

8. Lange NE, Litonjua A, Hawrylowicz CM, Weiss S. Vitamin D, the immune system and asthma. Expert review of clinical immunology. 2009;5(6):693-702.

9. Sabato V, Van De Vijver E, Hagendorens M, Vrelust I, Reyniers E, Fransen E, Bridts C, De Clerck L, Mortier G, Valent P, Ebo D. Familial hypertryptasemia with associated mast cell activation syndrome. Journal of Allergy and Clinical Immunology. 2014;134(6):1448-50.

10. Thakkar B, Katarkar A, Modh D, Jain A, Shah P, Joshi K. Deficiency of Vitamin D in Allergic-Rhinitis: a Possible Factor in Multifactorial Disease. J Clin Rhinol. 2014;7(3):112-6.

11. Lee SJ, Kang BH, Choi BS. Vitamin D serum levels in children with allergic and vasomotor rhinitis. Korean Journal of paediatrics. 2015;58(9):325.

12. Searing DA, Zhang Y, Murphy JR, Hauk PJ, Goleva E, Leung DY. Decreased serum vitamin D levels in children with asthma are associated with increased corticosteroid use. Journal of Allergy and Clinical Immunology. 2010;125(5):995-1000.

13. Abbas A, Littman A, Pillai S. IgE-Dependent Immune Responses and Allergic Disease. Abbas A, Lichtman AH, and Pillai S, eds. Cellular and Molecular Immunology, $7^{\text {th }}$ edition. Philadelphia: Elseviers, 2012: 423-37.

14. Ellis AK, Soliman M, Steacy L, Boulay MÈ, Boulet LP, Keith PK, Vliagoftis H, Waserman S, Neighbour H. The Allergic Rhinitis-Clinical Investigator Collaborative (AR-CIC): nasal allergen challenge protocol optimization for studying AR pathophysiology and evaluating novel therapies. Allergy, Asthma \& Clinical Immunology. 2015 Dec 1;11(1):16.

15. HYPPöNEN EL, Sovio U, Wjst M, Patel S, Pekkanen J, Hartikainen AL, JäRVELINB MR. Infant vitamin d supplementation and allergic conditions in adulthood: northern Finland birth cohort 1966. Annals of the New York Academy of Sciences. 2004;1037(1):84-95.

16. Wjst M, Hyppönen E. Vitamin D serum levels and allergic rhinitis. Allergy. 2007;62(9):1085-6.

17. Dogru M, Suleyman A. Serum 25-hydroxyvitamin D3 levels in children with allergic or nonallergic rhinitis. International journal of pediatric otorhinolaryngology. 2016;80:39-42. 
18. Arshi S, Ghalehbaghi B, Kamrava SK, Aminlou M. Vitamin D serum levels in allergic rhinitis: any difference from normal population?. Asia Pacific Allergy. 2012;2(1):45-8.

19. Devereux G, Litonjua AA, Turner SW, Craig LC, McNeill G, Martindale S, Helms PJ, Seaton A, Weiss ST. Maternal vitamin $\mathrm{D}$ intake during pregnancy and early childhood wheezing. The American journal of clinical nutrition. 2007;85(3):853-9.
20. Bäck O, Blomquist HK, Hernell O, Stenberg B. Does vitamin $\mathrm{D}$ intake during infancy promote the development of atopic allergy?. Acta dermato-venereologica. 2009;89(1):28-32.

21. Milner JD, Stein DM, McCarter R, Moon RY. Early infant multivitamin supplementation is associated with increased risk for food allergy and asthma. Pediatrics. 2004 ;114(1):27-32. 